\title{
A SOCIOLINGUÍSTICA INTERACIONAL NO DISCURSO POLÍTICO: UMA ANÁLISE DE TRECHOS ORAIS INTERATIVOS EM CONTEXTOS DA PANDEMIA DA COVID-19
}

\section{ARTIGO ORIGINAL}

MALDONADO, Gabriel Orlando Quiñones ${ }^{1}$

MALDONADO, Gabriel Orlando Quiñones. A Sociolinguística Interacional no discurso político: uma análise de trechos orais interativos em contextos da pandemia da COVID-19. Revista Científica Multidisciplinar Núcleo do Conhecimento. Ano 05, Ed. 08, Vol. 02, pp. 15-27. Agosto de 2020. ISSN: 2448-0959, Link de acesso: https://www.nucleodoconhecimento.com.br/letras/sociolinguistica-

\section{interacional}

\section{RESUMO}

O presente artigo fundamenta-se na área da Sociolinguística Interacional e é o resultado da análise de trechos dos diferentes discursos orais interativos do presidente do Brasil em contextos da pandemia da COVID-19. Coletou-se como referência de análise o corpus linguístico oral desses discursos registados nas diferentes mídias sociais espalhadas no Brasil e no mundo. A análise permitiu avaliar e interpretar os diferentes trechos orais interativos do discurso político, bem como

${ }^{1}$ Pós-doutor em Educação com investigação em Sociolinguística Musical Brasileira pela Universidade Virtual de Estudos Superiores - UNIVES no México (2020); Doutor em Ensino da Língua Portuguesa pela Bircham Internacional University em Madrid Espanha (2018); Mestre em Línguas, Culturas e Sociedades em Ambientes Multilíngues - Francês Língua Estrangeira pela "Université des Antilles" em Martinica (M1-2016 / M2-2018); Pós-graduado (Especialização) em Estudos de Língua Portuguesa: Investigação e Ensino pela Universidade Aberta de Portugal (2014): Graduado em Línguas Modernas, habilitação em Português e Francês, pela Universidad de Puerto Rico - Recinto de Río Pedras (2009). 
visa-se discutir sobre o vínculo confuso que teve a relação entre o discurso, a política e o coronavírus nesse tempo de pandemia que o nosso planeta tem encarado até a data de coleta dos dados, em julho de 2020.

Palavras-chave: Sociolinguística Interacional, análise de discurso oral, análise de discurso político, COVID-19.

\section{INTRODUÇÃO}

A Sociolinguística Interacional estuda, investiga e analisa os atos discursivos orais ou escritos no cotidiano dos diferentes componentes sociais. O discurso oral é deduzido por um tipo de atividade comunicativa por dois ou mais participantes que influenciam uns aos outros em uma troca de ações e reações verbais e não verbais nas interações narrativas. $\mathrm{Na}$ interação, os interlocutores ativam esquemas interpretativos que vão aperfeiçoando desde o primeiro contato da socialização. Essas representações nos permitem interpretar cada fragmento do discurso oral ou escrito e refletir acerca de toda a sua contextualização a partir da perspectiva individual de cada locutor até o ponto da interação com outros interlocutores.

A Sociolinguística Interacional (SI) é uma abordagem da análise de discurso que tem sua origem na busca de métodos replicáveis de análise qualitativa que explicam nossa capacidade de interpretar o que os participantes pretendem transmitir na prática comunicativa cotidiana. É sabido que os conversadores sempre confiam no conhecimento que, além da gramática e do léxico, se faz ouvir. Mas como esse conhecimento afeta a compreensão ainda não é suficientemente compreendido. (GUMPERZ, 2015, p. 9).

Os autores da Sociolinguística Interacional trabalham os processos de construções e interpretações contextualizadas dos significados a partir dos quais os interlocutores estabelecem relações entre o que é expresso na situação da interação com o conhecimento adquirido das outras experiências discursivas. $O$ conceito de dicas estratégicas de contextualização permite explicar como os participantes criam contexto e orientam os seus interlocutores no traço a uma interpretação apropriada das suas ações verbais ou não verbais. Os interlocutores de uma conversa confiam nessas estratégias para responder às suas intenções e investir significados ao que 
veem, perguntam e ouvem nos encontros interativos dos quais participam. As diferentes estratégias de contextualização discursivas incluem a linguagem corporal, bem como manipulação de objetos, gestos, postura, registro, alterações de estratégias discursivas, entre outras.

Os autores da Sociolinguística Interacional referem-se à necessidade de estudar as estratégias discursivas (GUMPERZ, 1982) que permitem, em contextos institucionais diversos, verificar que os constrangimentos da fala são os do relacionamento social (DIAMOND, 1996) e determinar de que modo se organizam as relações interlocutivas e interativas em contextos institucionais e mundanos a partir do estudo de rotinas verbais, dispositivos conversacionais e práticas discursivas que permitem a construção dos papéis discursivos (ALMEIDA, 2012).

\section{ENQUADRAMENTO TEÓRICO}

O discurso oral é a expressão mais básica da comunicação que existe entre os políticos e a comunidade. Acredita-se que devido à sua natureza principalmente oral, carece de moderação, sendo atribuídas características como imprevisíveis, descuidadas, incompletas, sem doutrinação e até vulgares. Nesta análise, o principal interesse é o discurso oral político durante a pandemia da Covid-19. Assim: "quando ocorre um incidente e o envolvimento espontâneo é ameaçado, a realidade é ameaçada" (GOFFMAN, 1967, p. 135). Serão estudadas as conversas obtidas a partir de discursos orais interativos do Presidente do Brasil, Jair Bolsonaro. É por isso que a sequência se aprofundará mais nesse tipo de discurso. Outro aspeto relevante do discurso oral é que a sua interlocução é maiormente presencial e é a transmissão presencial que o autoriza a ser espontâneo e rápido, sem produção formal prévia.

Quando os políticos se expressam em um determinado ato comunicativo, devem considerar o caso de adaptar à sua maneira de falar à eventualidade em que se encontram, pois, dessa forma: "eles serão forçados a aceitar alguns eventos como sinais convencionais ou naturais de algo que não está diretamente disponível para os sentidos" (GOFFMAN, 1967, p. 140). As exposições políticas exigem um certo cuidado na interação conversacional para que sejam compreensíveis diante da comunidade, 
envolvendo-se, nesse processo, aspectos como a postura corporal, relacionamento dos interlocutores e o jeito de transmitir a mensagem. São fatores muito importante que fomentam a sensação de veracidade.

Atividade conversacional bem sucedida, em que os processos de interssincronização entre os participantes funcionam de maneira bem regulada, desempenha, por conseguinte, esta função ritual de constituição de uma comunidade, em torno do reconhecimento do mesmo mundo vivido e da identidade de membro de uma mesma comunidade de vida (RODRIGUES, 2007, p. 11).

O princípio da cooperação estudado por Grice[2] é um princípio que versa sobre o comportamento linguístico a partir do qual as trocas conversacionais estão condicionadas, não só pelas produções linguísticas dos falantes, mas também pelas relações existentes entre os interlocutores. O princípio da cooperação é um princípio geral que se concretiza em outros princípios de comportamento, as chamadas máximas conversacionais: máxima de quantidade (informe aquilo que é necessário); máxima de qualidade (não diga aquilo que acredita ser falso); máxima de relevância (seja pertinente em relação ao objetivo da conversa) e a máxima de modo (seja ordenado, claro e breve). Tais conceitos, centrados na linguagem enquanto atividade social, evidenciam a insuficiência do código linguístico por si só e, além disso, a questão da violação destes princípios muitas vezes é traduzida em ironia e sarcasmo.

Os dados a serem analisados podem ser coletados a partir dos discursos feitos diariamente por quaisquer pessoas, profissionais e em interações políticas na frente de uma audiência ou a partir de mídias tecnológicas, como rádio, televisão ou redes sociais. Gumperz (1982, pp. 24-25) explica que:

o sociolinguística que trabalha nessa tradição começa registrando o discurso cotidiano de falantes selecionados de acordo com critérios de amostragem sociológica como representativos de um grupo ou comunidade em particular, e não de acordo com critérios de história da família ou formação linguística, como nos estudos dialetológicos anteriores. Além disso, os procedimentos de licitação partem dos métodos convencionais de questionário de dialeto, nos quais os falantes são questionados diretamente e solicitados a ilustrar ou produzir amostras de fala. 
O discurso político deve ter como objetivo provocar um certo comportamento nos seus receptores. Às vezes, os discursos políticos simplesmente informam sobre uma medida governamental, como o orçamento para o ano fiscal ou resoluções sobre medidas regulatórias. No entanto, as mesmas medidas, ao serem relatadas pelo mandatário em busca do apoio da população, possuem um caráter que gira em torno do discurso político interativo. A maioria dos discursos políticos tentam convencer os seus destinatários. Segundo Lopes (2009), existem evidências empíricas, em termos de comportamento sintático e prosódico, de que um relato da relação de justificação requer uma sequência de dois atos de fala, e, ainda, apontou que essa relação ocorre em diferentes tipos de textos argumentativos. Os discursos políticos para convencer aos interlocutores ou receptores devem ser discursos argumentativos.

Isso significa que eles estão afirmando algo e logicamente o apoiam com evidências ou raciocínio. No entanto, o argumento, no discurso político, difere do usado na retórica tradicional: no último, o argumento é usado para persuadir um adversário. Pelo contrário, no discurso político, o adversário não faz parte da comunicação.

A desarmonia interpessoal tende a se manifestar através de um comportamento rude (ou não polido) e uma falta de cooperação ou uma recusa em buscar relevância para os outros. Isso é especialmente o que acontece no contexto de gêneros discursivos de confronto, como o debate político, onde justas verbais são a regra e a polidez tem pouco lugar (SIMONIN, 2010, p. 28).

Os discursos políticos sempre têm destinatários diretos, ou seja, as pessoas a quem o locutor, neste caso, o presidente, dirige-se explicitamente. No entanto, também existem destinatários indiretos que devem receber a mensagem transmitida, mesmo que não sejam encaminhados diretamente a eles. Por exemplo, quando um presidente fala nas emissoras de televisão e nas emissoras de rádio, os cidadãos do seu país são os destinatários/receptores diretos. No entanto, a mensagem é recebida e interpretada por outros destinatários/receptores, como políticos estrangeiros, empresas internacionais ou linguistas dedicados à análise discursiva desses mandatários. Rodrigues (2007, p. 9), explica que: 
a interação discursiva é uma atividade que seres humanos realizam na presença física uns dos outros, dessa presença decorrendo para os que nela tomam parte o estatuto de participantes. É porque a presença física é o fator primeiro e fundamental da prática discursiva que todas as outras modalidades de prática discursiva têm na atividade conversacional o seu modelo e o seu fundamento.

Como mencionado, os discursos políticos visam explicitamente convencer o seu público, mas eles também fazem parte de uma estratégia que cria uma imagem do mandatário que pronuncia o discurso e envia as mensagens para identificar possíveis aliados ou inimigos. A maioria das estratégias discursivas usadas pelos políticos ao longo da história foram ferramentas que ficam nas suas práticas dentro da definição de estratégias de relações públicas. Portanto, implementar a definição mais ampla dessa terminologia varia em relação ao uso da persuasão, da retórica e da redação de opinião para convencer os outros de que o seu ponto de vista é o correto. Segundo Gumperz (1982, p. 188),

estão se tornando cada vez mais comuns em sociedades multiétnicas, à medida que os falantes de dialetos minoritários aproveitam os canais públicos de comunicação para divulgar suas opiniões. À medida que tentam convencer ou converter os outros à sua maneira de pensar, muitas vezes surgem discrepâncias sérias entre suas intenções declaradas e interpretações públicas de quais são seus objetivos.

A metáfora é, também, uma figura retórica que se refere a algo sem mencioná-lo, mas toma uma amostra disso que tem em comum. Nos discursos políticos, as metáforas são usadas para identificar os seus inimigos com ideias negativas. Elas também são usadas para aproximar os processos econômicos, financeiros, políticos e sociais complexos da simplicidade dos inexperientes. No entanto, essa simplificação é sempre ideológica: somente essa parte da realidade é selecionada e ajuda a convencer a população de que uma medida é positiva ou negativa. Segundo Gumperz (1982, p. 98),

o caso do uso metafórico é muito mais complexo. O mecanismo de sinalização envolvido é uma mudança nas dicas de contextualização, que não é acompanhada por uma mudança no tópico e em outros marcadores de contexto extralinguísticos que caracterizam a situação. Essa violação parcial das expectativas de ocorrência dá origem à inferência de que alguns aspectos das conotações, que em outros 
lugares se aplicam à atividade como um todo, devem ser tratados como afetando apenas a força ilocutória e a qualidade da fala em questão.

Atualmente, qualquer discurso baseado em mentiras é de importância singular, porque, hoje em dia, as organizações de publicidade e comunicações estão nas mãos dos diferentes especialistas desse ramo do saber e, quando recorrem à mentira, colocam toda a sua experiência e credibilidade em risco. Mentir no discurso político é uma manipulação de sinais e não de forças que sempre tenta colocar o receptor em uma posição mais baixa em relação a quem está mentindo. A vantagem de mentir em relação ao ataque direto é que, por acaso, o interlocutor não sabe que está sendo atacado. A confusão, do ponto de vista diário, está ligada à falta de clareza em relação à um tópico ou situação. Confusão também implica um nível de desordem. Se analisarmos o conceito da confusão causada pelo discurso político, o receptor pode dizer que está confuso porque tem dúvidas dos termos expostos na interação, porém, não possui clareza mental suficiente para decidir à respeito da pretensão do mandatário.

Contudo, nos discursos políticos, percebemos, com frequência, uma transmissão de dados errôneos que beneficia apenas quem quer a opressão do povo. A ordem pragmática corresponde à função da prática da ordem em que são transmitidas as palavras e a relevância das informações fornecidas. Dessa forma, os tópicos a serem discutidos são apresentados de acordo com o fornecimento dessas informações. A maneira como as palavras são organizadas é muito relevante para que sejam congruentes e formem um discurso compreensível. Isso significa que nos expressamos na ordem correta da sentença para obter boa coesão e coerência. Segundo Lopes (2009, p. 242): "é geralmente aceito que estabelecer coerência é um aspecto central da compreensão do discurso; portanto, processar o significado do discurso envolve recuperar as relações de coerência que integram as proposições individuais expressas no texto em um todo maior".

Coesão é o atributo pelo qual as asseverações de um texto estão vinculadas corretamente de um ponto de vista lexical e gramatical. Explica Fonseca (1994, p. 8), que "consubstancia-se, assim, a textura nos traços que fazem de um produto verbal 
um todo semântico unificado, como tal funcionando globalmente numa situação de comunicação, em que se inscreve por forma adequada".

\section{METODOLOGIA}

A investigação foi realizada a partir de uma amostra de trechos dos diferentes discursos orais interativos do presidente do Brasil, Jair Messias Bolsonaro[3]. Explicam Bastos e Biar, (2015, p. 103) que "de modo geral, pode-se dizer que as análises são de natureza qualitativa e interpretativa, interessadas, como se disse, no que acontece na vida social." Bolsonaro nasceu em Campinas, São Paulo, em 21 de março de 1955, e tem 65 anos de idade. Ele foi Capitão do Exército Brasileiro, Nioaque (MS), entre 1979-1981. O seu percurso acadêmico é baseado na área de Formação de Oficiais, Academia Militar das Agulhas Negras (AMAN) e Educação Física, Escola de Educação Física do Exército, entre outras. Nesta investigação, avaliar-se-ão vários trechos dos discursos feitos pelo presidente do Brasil nessa primeira metade do ano de 2020.

Esses trechos coletados foram publicados no jornal Folha de São Paulo. O presidente do Brasil fez inumeráveis transmissões no Palácio de Planalto e no Palácio da Alvorada na capital do Brasil, Brasília. Também tem participado de vários programas televisivos e radiais, transmitidos nas diferentes mídias sociais. Todos os trechos coletados estão vinculados às linhas de pensamento do presidente brasileiro referente à pandemia da COVID-19. Segundo Gumperz e Cook-Gumperz (1996, p. 10), "a tarefa inicial na análise é basicamente etnográfica, de coletar instâncias reais de situações interativas contendo todas as evidências internas para documentar os resultados". Apontam, também, que: "gravações de reuniões públicas ou transmissões públicas no local fornecem uma boa primeira fonte de materiais. Como muitas vezes é impossível coletar as informações básicas necessárias para as etapas posteriores da análise, também é necessário um trabalho de campo" (Idem, p. 10). 


\section{ANÁLISE DE TRECHOS DOS DISCURSOS ORAIS INTERATIVOS DO PRESIDENTE DO BRASIL}

Analisar-se-á o corpus linguístico oral, coletado nesses discursos políticos, registrados nas diferentes mídias sociais espalhadas no Brasil e no mundo. A análise permitirá avaliar e interpretar os diferentes trechos orais interativos do discurso político em contexto da pandemia da COVID-19 que o nosso planeta tem encarado até a data da coleta dos dados a seguir.

Trecho 1:

"Tem a questão do coronavírus também que, no meu entender, está superdimensionado, o poder destruidor desse vírus. Então talvez esteja sendo potencializado até por questão econômica, mas acredito que o Brasil, não é que vai dar certo, já deu certo".

O trecho 1 foi dito pelo presidente em 9 de março de 2020, em um congresso nos Estados Unidos, em Miami. Aqui podemos perceber um dos eixos de contraposição de Joaquim Fonseca (1992, p. 318), no qual o presidente do Brasil fez persuasão nesta citação do seu discurso. Segundo o autor há: "a contraposição entre dimensões acionais (direta ou indiretamente realizadas), nomeadamente elogio, critica/censura, persuasão, dissuasão".

Trecho 2:

"Vou ligar para o [ministro da Saúde, Luiz Henrique] Mandetta. Eu não sou médico, não sou infectologista. O que eu ouvi até o momento [é que] outras gripes mataram mais do que esta".

O trecho 2 foi expresso pelo presidente em 11 de março de 2020, em entrevista no Palácio da Alvorada, na capital brasileira, Brasília. A sociedade sabe que os discursos políticos, na maioria, não são projetados por especialistas em todos os ramos do conhecimento humano. Mas, nesse discurso, deveria ter tido transmitido, pelo menos, um mínimo de capacidade e inteligência para contribuir com a sua mensagem: calma, respeito, sensibilidade e proteção. Duarte (2005, pp. 294-295), diz que "o locutor e alocutário partilham saberes e crenças anteriores ao momento em que comunicam e, 
se isso é valido para as trocas verbais entre atores que são políticos, também o é para o jornalista que escreve um texto e os leitores que o leem".

Trecho 3:

\section{Sequência}

Jair M. Bolsonaro

@jairbolsonaro

- Superar este desafio depende cada

um de nós. O caos só interessa aos

que querem o pior para o Brasil. Se,

com serenidade, população e

Governo, junto com os demais

poderes, somarmos os esforços

necessários para proteger nosso povo,

venceremos não só este mal como

qualquer outro!

\section{$17: 45 \cdot 17 / 03 / 2020 \cdot$ Twitter for Android}

\subsection{Retweets e comentários 45,1K Curtidas}

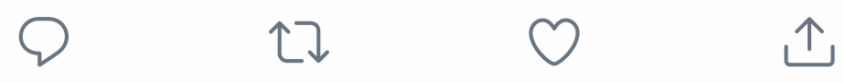

O trecho 3 foi tirada do Twitter, escrito pelo presidente em 17 de março de 2020, em uma publicação na sua conta oficial nessa rede social. Compreendemos aqui a ideia de que o presidente atribui responsabilidade a cada indivíduo, porque expressa que "superar este desafio depende de cada um de nós". Também se pode entender que 
está se esquivando da responsabilidade do governo e aplicando-a individualmente. Segundo Rodrigues (2007), as modalidades discursivas, como é o caso, por exemplo, da correspondência epistolar, telefônica ou telemática " na escrita e na leitura de obras literárias ou de qualquer outra modalidade de discurso escrito, só podemos entender o sentido daquilo que escrevemos ou lemos porque pressupomos a presença física de interlocutores" (RODRIGUES, 2007, p. 9). Alude, ainda, que: "cada uma dessas outras modalidades de prática discursiva depende de dispositivos técnicos que não conseguem assegurar a totalidade das dimensões da presença física envolvidas na atividade conversacional face a face" (Idem, p. 9).

Trecho 4:

"O que se passa no mundo mostra que o grupo de risco é de pessoas acima de 60 anos. Então, por que fechar escolas? Raros são os casos fatais, de pessoas sãs, com menos de 40 anos de idade".

Trecho 5:

"Pelo meu histórico de atleta, caso fosse contaminado pelo vírus, não precisaria me preocupar, nada sentiria ou seria acometido, quando muito, de uma gripezinha ou resfriadinho, como bem disse aquele conhecido médico, daquela conhecida televisão".

Os trechos 4 e 5 foram relatados pelo presidente em 24 de março de 2020, nas diferentes emissoras de rádio e televisão. No trecho 4, percebemos a incredulidade do presidente na sua interação oral. Naquele momento, foi declarado que o grupo de risco era o idoso, portanto, com base na sua arrogância e ignorância, não acredita que esta doença afete a população jovem-adulta. A posição do seu discurso político sempre apresenta uma difícil compreensão e um ponto contraditório, nesta situação para os especialistas do ramo da saúde. Segundo Kerbrat-Orecchioni (1980, p. 33), "é necessário admitir para cada mensagem a existência de receptores adicionais e aleatórios, cuja natureza o remetente não pode prever nem, consequentemente, a interpretação que eles darão à mensagem produzida." No trecho 5 , o presidente falanos sobre uma experiência de vida com a explicação do seu histórico de atleta. 
Também expõe os seus próprios motivos e minimiza o efeito da doença, chamando-a de "gripezinha". $\mathrm{Na}$ análise das narrativas de experiência de vida em emissões de rádio, os participantes realizam espontaneamente identidades locais, relevantes para a construção de uma imagem de si próprios com um determinado estatuto: participantes ratificados ou como "experts", identificados em função de parâmetros como o sexo, a profissão, a idade ou relativamente a uma história vivida, como testemunho de uma vivência que queiram ver partilhada (ALMEIDA, 2011).

Trecho 6:

"Esse vírus é quase como uma chuva, vai atingir você", acrescentou Bolsonaro. Alguns tem que tomar um maior cuidado com esse fenômeno. Acontece, infelizmente acontece".

Trecho 7:

"Vamos tomar cuidado, em especial os mais idosos, que têm comorbidade. E os mais jovens, tomem cuidado. Mas se forem acometidos do vírus, fiquem tranquilos porque, para vocês, a possibilidade de algo mais grave é próximo de zero".

Os trechos 6 e 7 foram comunicados pelo presidente em 7 de julho de 2020 para as emissoras de CNN Brasil, Record e TV Brasil, que foram convocadas para expor a sua nova e importante mensagem para o povo. A quarentena globalmente implantada para todas as pessoas, refere-se ao isolamento social como um mecanismo de proteção articulado em todo o mundo para manter um grau consistente de normalidade e manter a saúde. No trecho 6 , vemos que o presidente compara a COVID-19 com a chuva e diz que a qualquer momento isso afetará você. Nesse discurso, o trocadilho está presente para minimizar a realidade da doença. Assim: "em algumas trocas de conversação, uma regra de par de adjacência pode ser violada. Poderíamos simplesmente descartar tais trocas como conversas "não gramaticais", não "reais" e não existem dados adequados" (BILMES, 1988, p. 46).

No trecho 7, sem nenhuma base científica em mão, o presidente expressa que os jovens devem ter calma, já que a possibilidade de o vírus os afetar está mais próxima de zero. Nesse dia ele "confirmou que contraiu" a COVID-19 e que está "perfeitamente 
bem". O uso do sarcasmo na comunicação pode nos tornar uma péssima jogada quando queremos ganhar a confiança dos outros. Os trocadilhos não nos oferecem uma mensagem forte e clara; pelo contrário, esses trocadilhos são os promotores de novas perguntas que buscam esclarecer as dúvidas que ainda persistem. presidente Bolsonaro no seu discurso está violando a máxima conversacional de Grice, porque não satisfez a máxima da relação. Ele não foi relevante nem pertinente na sua exposição.

Segundo Duarte (2005, p. 293): "as pressuposições e outros implícitos são estratégias discursivas utilizadas pelo locutor para, indireta e sub-repticiamente, impor determinadas ideias ou opiniões: "Os políticos têm, de facto, uma enorme habilidade (ou necessidade...) de dizer-não-dizendo ou de não-dizer-dizendo - o que, para o caso, vem a dar no mesmo".

\section{CONSIDERAÇÕES FINAIS}

A máxima de modo é a mais violada nas mensagens políticas do presidente brasileiro por não projetar clareza nos trechos analisados. Essa violação pública e aberta permitiu analisar e interpretar adequadamente o que significava e o que foi exposto na sua interação. Sabe-se que a situação do isolamento causado pela pandemia da COVID-19 é crucial e é necessária a clareza nas mensagens para que as pessoas possam obter a melhor interpretação possível. Pessoas que não são informadas ou não têm conhecimento da causa e efeito desse novo vírus, ou das expressões idiomáticas do português do Brasil, dificilmente conseguiriam interpretar o que desejava comunicar o presidente na maioria das suas mensagens. Nas transmissões de rádio e televisão, mesmo nas diferentes redes sociais do presidente (locutor), não foram respeitadas as máximas de Grice e é exatamente o que desencadeia o medo e a confusão dos receptores.

Foi visto como o discurso político interativo indireto é comum à quase todos os exemplos estudados, uma vez que comunicar algo diferente do que é literalmente dito permite o jogo linguístico nas interações e as interpretações dos receptores. Esse ato indireto é caracterizado pela inconsistência entre forma e significado; portanto, o 
significado pragmático ao qual o locutor (presidente do Brasil) atribui aos receptores (brasileiros e estrangeiros) é composto dessas mensagens de confusão com o duplo significado, metáforas e, muitas vezes, de natureza sarcástica. Como disse Goffman, é um efeito dramatúrgico que surge difusamente de uma cena que é apresentada (1959). Como foi apresentado nas páginas anteriores, a Sociolinguística Interacional proporciona as ferramentas adequadas para fazer uma boa análise dos discursos políticos, como foi apresentada a análise de trechos orais interativos no contexto de pandemia provocado pela COVID-19.

Há muito tempo o medo está presente no nosso dia a dia, em qualquer lugar, país ou cultura. O medo foi incorporado em vários trechos do discurso político como base ou suporte para o domínio das controvérsias subjacentes em face à pandemia da COVID19. O medo é um sentimento involuntário, que, neste caso, é criado pelas mensagens difusas e confusas transmitidas nos trechos não científicos do presidente brasileiro nessa primeira metade do ano de 2020. Essas mensagens submergem seu povo à um nível de ansiedade frustrante e incalculável. Interferir nos sentimentos ao assumir o discurso político é um exercício de irresponsabilidade por parte dos líderes em cada interação oral ou escrita com seus interlocutores, pois a indexicalidade aprimora ou amplia a capacidade de entender como conceitos como identidade, emoções, posições afetivas e ideologia trabalham em interação (GÜNTHNER, 2011).

Quando nossos políticos recorrem ao medo, o equilíbrio entre razão e as emoções são confrontados e o povo corre o risco de perder a estabilidade emocional. O discurso político é a principal ferramenta para comunicar e informar tudo o que acontece com o governo no poder. Esses discursos podem trazer comunicação persuasiva, com técnicas de argumentação e estratégias psicológicas para impactar as pessoas da maneira que entenderem melhor. No discurso político, o processo de comunicação e o processo de recebimento de uma mensagem persuasiva ou confusa fazem parte da descrição característica dos políticos há muitos anos. Primeiro, é feita uma inferência sobre o significado, ou seja, uma interpretação dessa mensagem e, finalmente, uma reação, uma resposta, muitas vezes emocional, que é desencadeada como uma consequência da referida interpretação desse discurso político. 
Os diferentes trechos políticos analisados são interpretados como mensagens com um significado frio e neutro, carente da emoção de um ser humano com valores, que realmente quer o bem-estar do povo e que deveria dirigir e manter a sua segurança.

\section{REFERÊNCIAS}

ALMEIDA, C. A. de. Aspectos semânticos e pragmáticos da co-construção de identidades discursivas em narrativas de experiência de vida produzidas por participantes de emissões nocturnas de rádio" In: COSTA, A.; FALÉ, I.; BARBOSA, P. (Orgs.) Textos Selecionados XXVI Encontro Nacional da Associação Portuguesa de Linguística. Lisboa: APL, 2011, pp. 35-48.

ALMEIDA, C. A. de. A construção da ordem interaccional na rádio. Contributos para uma análise linguística do discurso em interacções verbais. Porto: Edições Afrontamento, Biblioteca das Ciências Sociais, 2012.

BASTOS, L. C.; BIAR, L. de. A. Análise de narrativa e práticas de entendimento da vida social. DELTA: Documentação e estudos em linguística teórica e aplicada, v. 31 , n. $4,2015$.

BILMES, J. Category and rule in conversation analysis. IPRA papers in pragmatics, v. 2, n. 1-2, p. 25-59, 1988.

DUARTE, I. M. Falar claro a mentir. Estudos em homenagem ao Professor Doutor Mário Vilela. 2005. Disponível em: https://repositorioaberto.up.pt/bitstream/10216/7890/2/73321.pdf. Acesso em: 03 ago. 2020.

FONSECA, J. Linguística e texto/discurso: teoria, descrição, aplicação. Lisboa: Ministério da Educação, 1992.

FONSECA, J. O lugar da Pragmática na Teoria e na Análise Linguística. In: FONSECA, J. (Org.). Pragmática linguística. Porto: Porto Editora, 1994. 
GOFFMAN, E. Presentation of Self in Everyday Life. New York: Doubleday Anchor, 1959.

GOFFMAN, E. Interaction Ritual. New York: Doubleday Anchor, 1967.

GRICE, H. P. Logic and conversation. In: Speech acts, 1975.

GUMPERZ, J. Discourse strategies. Cambridge: Cambridge University Press, 1982.

GUMPERZ, J. Sociolinguistique interactionnelle. Une approche interprétative. Paris: L'Harmattan, 1989.

GUMPERZ, J. J.; Cook-Gumperz, J. (Ed.). Language and social identity. New York: Cambridge University Press, 1996.

GUMPERZ, J. J. 11 Interactional Sociolinguistics: A Personal Perspective. In: TANNEN, D.; HAMILTON, H. E.; SCHIFFRIN, D. The handbook of discourse analysis. Reino Unido: Wiley Blackwell, 2015.

GÜNTHNER, S. The construction of emotional involvement in everyday German narratives-interactive uses of 'dense constructions. Pragmatics, v. 21, n. 4, p. 573592, 2011.

KERBRAT-ORECCHIONI, C. L'énonciation. De la subjectivité dans le langage. Paris: Armand Colin, 1980.

LOPES, A. C. M. Justification: a coherence relation. Pragmatics, v. 19, n. 2, p. 241252, 2009.

Presidência da República Planalto. Biografia do Presidente. 2020. Disponível em: https://www.gov.br/planalto/pt-br/conheca-a-presidencia/biografia-do-presidente. Acesso em: 14 jul. 2020.

RODRIGUES, A. D. Processos cognitivos e estratégias de comunicação. Revista do Centro de Estudos Judiciários, v. 7, p. 1-27, 2007. 
SIMONIN, O. (Im) politesse, coopération et principes d'inférence. Lexis. Journal in English Lexicology, n. 2, 2010.

\section{APÊNDICE - REFERÊNCIAS DE NOTA DE RODAPÉ}

2. Grice, H. Paul, 1975, "Logic and conversation"

3. https://www.gov.br/planalto/pt-br/conheca-a-presidencia/biografia-do-presidente

Enviado: Julho, 2020.

Aprovado: Agosto, 2020. 